\title{
Appeals and Cultural Values in Chinese Television Commercials
}

\author{
Feng Shen ${ }^{1}$ \\ ${ }^{1}$ Haub School of Business, Saint Joseph's University, Philadelphia, USA \\ Correspondence: Feng Shen, Haub School of Business, Saint Joseph's University, Philadelphia, PA 19131, USA. \\ Tel: 1-610-660-2258. E-mail: fshen@sju.edu
}

Received: December 22, 2012

Accepted: February 4, 2013

Online Published: March 11, 2013

doi:10.5539/ibr.v6n4p25

URL: http://dx.doi.org/10.5539/ibr.v6n4p25

\begin{abstract}
China is the world's fastest growing advertising market, and better understanding of the Chinese market is therefore crucial for both domestic and international advertisers. The objective of this study is to investigate two aspects of Chinese advertising that are under-explored in the literature. One is the use of appeals and cultural values in television commercials for indigenous Chinese brands. The other is the difference in the use of appeals and cultural valuesacross product categories. A content analysis is conducted to examine the use of appeals and cultural values in 428 prime-time Chinese television commercials for indigenous brands. While overall there is more use of rational appeals and less use of emotional appeals in goods advertising than in service advertising, the use of appeals and cultural values varies within goods categories. There is in fact more use of emotional appeals than rational appeals in the beauty and personal care category and the clothing category, and there is no difference in appeals in the food and drink category. These results are likely due to product characteristics, that is, rational appeals are associated with utilitarian products and emotional appeals are associated with hedonic products. The findings reported in this study have important managerial implications, particularly for international advertisers, to choose the right appeal and cultural values for their products.
\end{abstract}

Keywords: international advertising, Chinese television commercials, adverting appeals, cultural values, content analysis

\section{Introduction}

Interest in appeals and cultural values is prevalent in the literature of international advertising, and there are a growing number of studies that analyze advertising appeals and values in China, the world's fastest growing advertising market (Weber, 2000), in the current Western-culture centered globalization. This line of research helps identify the interplay of appeals and values as reflected in Chinese advertising and makes substantial contribution to the knowledge base of international advertising, which is crucial for both domestic and international advertisers. The objective of this study is to investigate two aspects of Chinese advertising that are under-explored in the literature. One is the use of appeals and cultural values in television commercials for indigenous Chinese brands. The other is the difference in the use of appeals and cultural valuesacross product categories. In this paper, appeals refer to rational and emotional appeals. The two appeals stem from the idea that a consumer's decision-making can be either thought-based (rational) or feeling-based (emotional) (Hoyer \& Maclnnis, 2004). In the remainder of the article, I first provide a literature review of cultural values and advertising appeals. Second, I report a content analysis that examined hypotheses and questions regarding appeals and cultural values in Chinese television commercials. Finally, I discuss the implications of this study as well as limitations and directions for future research.

\subsection{Culture and International Advertising}

Because culture is a key aspect in the development of international advertising strategies (Duncan, 2002), cultural studies have substantial impacts on international advertising research. But cultural theories have to be integrated with what has been known about advertising, for example, theories about creative strategy and execution, to account for the dynamics of international advertising (Taylor, 2005). This section provides a review of approaches to cultural values and empirical studies that attempted to link those approaches to advertising appeals.

\subsubsection{Dimensional and Discrete Approaches to Cultural Values}

Probably one of the most famous cultural theories, Hofstede's (1980) four-dimensional approach has been used by an increasing number of researchers to interpret the dynamics of international advertising and marketing (Mueller, 
2004). The four dimensions are individualism, power distance, uncertainty avoidance, and masculinity (Hofstede, 1980). However, one limitation of Hofstede's work lies in the fact that those cultural dimensions originate from an extensive survey about work-related values in worldwide subsidiaries of a large multinational corporation (Hofstede, 1980) and thus may not perfectly fit cultural values conveyed through or reflected in advertising (Taylor, 2005). For example, the individualism dimension was measured by asking respondents the importance of "personal time (have a job which leaves you sufficient time for your personal life) ... training (have training opportunities - to improve your skills or learn new skills)" (Hofstede, 1980, p. 220). The power distance dimension was measured by asking respondents "the "employees afraid' question ... for a perception of the behavior of fellow employees ... the 'perceived manager' question ... for a perception of the behavior of the boss" (p. 101). The uncertainty avoidance dimension was measured by asking respondents questions about "rule orientation, employment stability, and stress" (p. 161). Finally, the masculinity dimension was measured by comparing gender difference in perceived importance of "job content goals ... and ... private life goals" (p. 274).

While Hofstede's dimensional approach to cross-cultural differences barely touches upon consumer characteristics or product attributes, there is a discrete approach to cultural values in advertising developed by Pollay (1983). This discrete approach can be traced back to early initiatives to categorize motives in advertising (Starch, 1923) and human needs (Murray, 1938), followed by efforts to classify rhetorical devices in advertising (Andren, Ericsson, Ohlsson, \& Tannsjo, 1980) and instrumental versus terminal values (Rokeach, 1973), and it combines the work of both advertising research and cultural studies. There are 42 values in Pollay's cultural framework and they were validated through a content analysis of print advertisements (Pollay, 1983). Because the Pollay framework was established in a strictly Western context and supported by the content analysis that used Western print advertisements published from the turn of the 20th century to the 1980s rather than a comparison of all types of advertisements that would vary by country or cultural origin, some effort has been devoted to an integration of this discrete approach to cultural values in Western advertising with Hofstede's dimensional approach to worldwide work-related cultural values.

In one of the studies that attempted to integrate the two approaches, Albers-Miller (1996) selected one cultural area from each of the 11 country clusters identified with the Hofstede dimensions (1980, p. 336), namely Brazil, Chile, Mexico, the U.S., India, Japan, Taiwan, Israel, Finland, France, and South Africa, and content analyzed print advertisements of the 11 areas with Pollay's (1983) value scheme (pp. 80-84). Because the cultural dimensions of the 11 areas were already known, the results were used to relate the values of Pollay to the dimensions of Hofstede. It turned out that half or 21 of the original 42 values proposed by Pollay could be associated with a single end of each of the four dimensions. To be more specific, "distinctive," "independence," and "self-respect" were associated with high individualism, whereas "popular," "affiliation," and "community" with low individualism or high collectivism. "Ornamental," "dear," "vain," and "status" were associated with high power distance, whereas "cheap," "wisdom," and "plain" with low power distance. "Durable," "safety," and "tamed" were associated with high uncertainty avoidance whereas "adventure" with low uncertainty avoidance. "Effective," "convenient," and "productivity" were associated with high masculinity, whereas "natural" with low masculinity or high femininity (Albers-Miller, 1996).

Although Albers-Miller argued that cultural values might vary by product category and purposely selected two service (finance and travel) and two goods (office supply and apparel) categories in her study, she did not report whether there was any difference between the product categories. In another study by her and Stafford (Albers-Miller \& Stafford, 1999), they did look into cultural differences between product categories and attempted to connect cultural values to advertising appeals.

\subsubsection{Cultural Values and Advertising Appeals}

Prior to a review of Albers-Miller and Stafford's study in 1999, it is necessary to mention some general propositions about advertising appeals. Research of consumer behavior indicates that product attitude, purchase intention, and purchase behavior can be formed either cognitively or affectively; therefore, advertisers can persuade consumers either through rational appeals that aim to influence consumers' thoughts or beliefs about an offering or through emotional appeals that aim to influence consumers' emotional experiences with the offering (Hoyer \& Maclnnis, 2004).

While Hofstede (1980) argued that rationality and emotionality could be associated with work-related cultural values, its implication for the relationship between rational/emotional appeals of advertising and advertising-related cultural values was largely unknown. After Albers-Miller (1996) found that Pollay's (1983) advertising-related cultural values could be used to represent Hofstede's (1980) work-related cultural values, Albers-Miller and Stafford (1999) further categorized Pollay's cultural values into rational and emotional appeals 
and helped translate Hofstede's proposition about the relationship between rationality/emotionality and cultural values into advertising research.

In their study, Albers-Miller and Stafford (1999) content analyzed print advertisements from Brazil, Mexico, Taiwan, and the U.S. to examine advertising appeals across cultural areas. They used the 42 values of Pollay to code the advertisements in the first round of coding, categorized the 42 values into emotional or rational appeals in the second round of coding, and created a new coding scheme with 14 values as rational appeals and 28 values as emotional appeals (p. 48). They chose the advertisements from the same service (finance and travel) and goods (office supply and apparel) categories in the early study (Albers-Miller, 1996).

Their analysis indicated that the U.S. advertisements used significantly more rational appeals than did the Taiwan advertisements, with those of Mexico and Brazil falling between. Conversely, the Taiwan advertisements used significantly more emotional appeals than did the U. S. advertisements, again with those of Mexico and Brazil falling between. Because the U.S. well represents the West and Taiwan the East, the sharp contrast in the advertisement content of the two cultural areas seems to suggest that rational appeals would be typical of Western cultures whereas emotional appeals typical of Eastern cultures (Wang, 2000). Nevertheless, when comparisons were made within the Taiwan advertisements in terms of goods and service, the goods advertisements used more rational appeals than emotional appeals whereas the service advertisements used more emotional appeals than rational appeals. That finding is in line with the fact that service is fundamentally different from goods in terms of intangibility and is more likely to be advertised through emotional appeals (Swaminathan, Zinkhan, \& Reddy, 1996).

Although Albers-Miller and Stafford (Albers-Miller, 1996; Albers-Miller \& Stafford, 1999) helped establish an international advertising appeals/cultural value framework that went beyond Hofstede's work-related cultural dimensions, their research was limited to print advertisements and the comparisons were made between broad categories such as services and goods. But there are studies that compare a much wider range of products in other types of media, for example, television commercials.

\subsubsection{Cultural Values and Product Characteristics}

Lin (2001) compared television commercials in China and the U.S. through content analysis. The product categories in the commercials were automobile, beauty and personal care, clothing, food and drink, household appliances, medicine, services, travel, industrial products, and miscellaneous. The coding scheme was based on Muller's (1987) cultural value index, which included group/consensus, individual/independence, soft-sell appeal, hard-sell appeal, veneration of elderly/tradition, modernity/youth, status, product merit, oneness with nature, and time orientation. A close look into Muller's coding scheme indicates that there is more similarity than difference between Muller's cultural value index and the above-reviewed cultural frameworks and advertising appeals. For example, group/consensus and individual/independence correspond to the individualism dimension, soft sell and hard sell correspond to emotional and rational appeals, and tradition, status, nature, youth, and modernity are in Pollay's (1983) value scheme.

The results indicated that the values varied by product category and country. For example, "food and drink" was more closely associated with "soft-sell" in the Chinese commercials than in the U.S. commercials, but it was more closely associated with "independence" in the U.S. commercials than in the Chinese commercials. However, Lin (2000) did not report the use of the cultural values by product category in the Chinese commercials or the U.S. commercials, for example, she did not report whether "food and drink" was more closely associated with "soft-sell" than were the other product categories in the Chinese commercials. This type of information was provided in Cheng and Schweitzer's (1996) study.

Cheng and Schweitzer (1996) also compared television commercials in China and the U.S. through content analysis, and the commercials had the same product categories as those in Lin's (2001) study. The coding scheme was primarily developed from those of Pollay (1983) and Mueller (1987) and had 32 cultural values (Cheng \& Schweitzer, 1996, pp. 29-30).

The results provided more details as to how cultural values varied by product category and country. For example, in the Chinese commercials, "food and drink" was more closely associated with "tradition" than the other categories. In the U.S. commercials, it was more closely associated with "enjoyment" than most of the other categories (Cheng \& Schweitzer, 1996).

\subsection{Categorization, Hypotheses, and Research Questions}

Based on the literature review discussed above, cultural values identified in previous research are categorized into rational or emotional appeals in Table 1, and similar values are combined. There are 47 values, 16 in the category 
of rational appeals and 31 in the category of emotional appeals.

According to the literature review, there is more use of rational appeals in goods advertisements and more use of emotional appeals in service advertisements in Eastern cultures such as Taiwan (Albers-Miller \& Stafford, 1999). To extend this finding to television commercials for indigenous Chinese brands, it is hypothesized:

$H 1$. There is more use of rational appeals than emotional appeals in goods television commercials for indigenous Chinese brands.

$H 2$. There is more use of emotional appeals than rational appeals in service television commercials for indigenous Chinese brands.

Although there are some findings about the difference in the use of appeals/cultural values between product categories, the product categories were too broad (e.g., Albers-Miller \& Stafford, 1999) or the notion of rational/emotional appeals was not tested (e.g., Cheng \& Schweitzer, 1996). Therefore, two research questions are proposed.

$R Q 1$. What are the differences between the use of rational and emotional appeals in each product category's television commercials for indigenous Chinese brands?

$R Q 2$. What specific values under the rational and emotional appeals are the most frequently used in each product category's television commercials for indigenous Chinese brands?

Table 1. Appeals and cultural values

\begin{tabular}{|c|c|c|}
\hline Rational Appeals & Emotional Appeals & \\
\hline Cheapness $^{\mathrm{a}} /$ Economy $^{\mathrm{c}}$ & Adventure $^{\mathrm{a}}$ & Nurturance $^{\mathrm{a}}$ \\
\hline Convenience $^{\mathrm{a}}$ & Affiliation $^{\mathrm{a}}$ & Ornamental $^{\mathrm{a}} /$ Beauty $^{\mathrm{c}}$ \\
\hline Competition $^{\mathrm{b}}$ & Causalness ${ }^{\mathrm{a}}$ & Patriotism $^{\mathrm{c}}$ \\
\hline Durability $^{\mathrm{a} / \text { Quality }^{\mathrm{c}}}$ & Community $^{\mathrm{a}}$ & Plainness $^{\mathrm{a}}$ \\
\hline Effectiveness $/ \mathrm{Quality}^{\mathrm{c}}$ & Courtesy $^{\mathrm{c}}$ & Popularity ${ }^{\mathrm{a}}$ \\
\hline Health $^{\mathrm{a}}$ & Dearness $^{\mathrm{a}}$ & Relaxation $^{\mathrm{a}} /$ Leisure $^{\mathrm{c}}$ \\
\hline Independence $^{\mathrm{a}} /$ Individualism $^{\mathrm{b}}$ & Distinctiveness $^{\mathrm{a}} /$ Uniqueness $^{\mathrm{c}}$ & Respect for the Elderly ${ }^{\mathrm{b}}$ \\
\hline Modernity $^{\mathrm{a}}$ & Enjoyment $^{\mathrm{a}} /$ Leisure $^{\mathrm{c}}$ & Security $^{\mathrm{a}}$ \\
\hline Naturalness ${ }^{\mathrm{a}}$ & Family $^{\mathrm{a}}$ & Sexuality ${ }^{\mathrm{a}}$ \\
\hline Neatness $^{\mathrm{a}}$ & Frailness $^{\mathrm{a}}$ & Status $^{\mathrm{a}} /$ Wealth $^{\mathrm{c}}$ \\
\hline Tamed $^{\mathrm{a}}$ & Freedom $^{\mathrm{a}}$ & Succorance $^{\mathrm{a}}$ \\
\hline Technology ${ }^{\mathrm{a}}$ & Humility $^{\mathrm{a}}$ & Tradition $^{\mathrm{a}}$ \\
\hline Safety $^{\mathrm{a}}$ & Magic $^{\mathrm{a}}$ & Untamed $^{\mathrm{a}}$ \\
\hline Productivity ${ }^{\mathrm{a}}$ & Maturity $^{\mathrm{a}}$ & Vainness $^{\mathrm{a}}$ \\
\hline Wisdom $^{\mathrm{a}}$ & Modesty $^{\mathrm{a}}$ & Youth $^{\mathrm{a}}$ \\
\hline Work $^{\mathrm{c}}$ & Morality $^{\mathrm{a}}$ & \\
\hline
\end{tabular}

\section{Method}

\subsection{Sampling}

Television commercials aired in primetime during the fall sweeps, the most important advertising season (Lin, 2001), of 2012 constitute the sampling universe. A total of 1,712 non-redundant 30-second-long commercials of indigenous Chinese brands were collected through AdMonitor of MeiHua Information (http://www.meihua.info/adm), a business intelligence firm that provides the most comprehensive tracking service of advertising campaigns in China covering 104 television channels. Through simple random sampling, 25\% or 428 of the commercials were content analyzed.

\subsection{Coding Procedure}

The coding unit was one complete television commercial. Each commercial was first coded into product categories identified by Cheng and Schweitzer (1996), Albers-Miller (1996), and Lin (2001). Because an advertisement can have more than one value (Pollay, 1983), the commercial was next coded for all the 47 values in Table 1 . When a value was found present in a commercial, the value was coded as " 1 "; otherwise as " 0 ." The values were averaged to create one rational appeal score and one emotional appeal score for each product category. 
Two bilingual (English/Chinese) graduate students, with no knowledge of the research objective, received detailed coding schemes from studies reviewed above, i.e., Pollay (1983, pp. 80-84), Mueller (1987, pp. 52-53), and Cheng and Schweitzer (1996, pp. 29-30), and coded the commercials. The inter-coder reliability was .92 with Holster's formula (North, Holster, Zaninovich, \& Zinnes, 1963), which is highly acceptable (Lombard, Snyder-Duch, \& Bracken, 2002).

\section{Results}

\subsection{Hypotheses}

Scores of rational and emotional appeals as well as comparisons are reported in Table 2. Through paired comparison, it was shown that goods commercials used more rational appeals than emotional appeals and that service commercials used more emotional appeals than rational appeals. The two hypotheses were supported.

\subsection{Research Question 1}

To address Research Question 1, paired comparisons within each goods and service category are also reported in Table 2. For the goods categories, commercials of automobile, household appliances, and medicine used more rational appeals than emotional appeals, whereas those of beauty and personal care and clothing used more emotional appeals than rational appeals. In addition, the use of the two appeals did not differ in the food and drink category. For the service categories, commercials of both finance and travel used more emotional appeals than rational appeals.

Table 2. Comparisons of appeals by product category

\begin{tabular}{|c|c|c|c|c|c|c|c|}
\hline \multirow[b]{2}{*}{ Product categories ${ }^{\mathrm{a}}$} & \multicolumn{2}{|c|}{ Rational } & \multicolumn{2}{|c|}{ Emotional } & \multirow[b]{2}{*}{$t$} & \multirow[b]{2}{*}{$d f$} & \multirow[b]{2}{*}{$p$} \\
\hline & Mean & SD & Mean & SD & & & \\
\hline Goods $(n=371)$ & .63 & .48 & .51 & .50 & 7.33 & 370 & $<.001$ \\
\hline Automobile $(n=28)$ & .86 & .36 & .25 & .44 & 6.46 & 27 & $<.001$ \\
\hline Beauty and personal care $(n=63)$ & .51 & .50 & .63 & .49 & -3.00 & 62 & $<.01$ \\
\hline Clothing $(n=39)$ & .46 & .51 & .62 & .49 & -2.63 & 38 & $<.05$ \\
\hline Food and drink $(n=90)$ & .73 & .47 & .67 & .52 & 1.75 & 89 & .08 \\
\hline Household appliances $(n=82)$ & .71 & .46 & .35 & .48 & 6.66 & 81 & $<.001$ \\
\hline Medicine $(n=69)$ & .70 & .46 & .49 & .50 & 4.16 & 68 & $<.001$ \\
\hline Service $(n=57)$ & .40 & .53 & .70 & .53 & -3.98 & 56 & $<.001$ \\
\hline Finance $(n=41)$ & .39 & .49 & .61 & .54 & -2.96 & 40 & $<.01$ \\
\hline Travel $(n=16)$ & .44 & .63 & .94 & .44 & -2.74 & 15 & $<.05$ \\
\hline
\end{tabular}

Notes: $n$ in this column refers to the number of commercials in each category.

\subsection{Research Question 2}

To address Research Question 2, the use of the 47 cultural values in Table 1 in each product category was computed, and the most frequently used cultural values in each product category were reported below.

In terms of the most frequently used cultural values under the rational appeals across the goods categories, durability was used the most frequently in both the automobile category (34\%) and the household appliances category $(32 \%)$, neatness in the beauty and personal care category $(14 \%)$, independence in the clothing category $(12 \%)$, naturalness in the food and drink category $(23 \%)$, and health in the medicine category $(42 \%)$. On the other hand, in terms of the most frequently used cultural values under the emotional appeals across the goods categories, status was used the most frequently in the automobile category $(11 \%)$, ornamental in both the beauty and personal care category (47\%) and the clothing category (39\%), enjoyment in the food and drink category (19\%), family in the household appliances category (14\%), and freedom in the medicine category $(10 \%)$.

In terms of the most frequently used cultural values under the rational appeals in the two service categories, wisdom was used the most frequently in the finance category (19\%), and naturalness in the travel category (12\%). In terms of the most frequently used cultural values under the emotional appeals in the two service categories, security was used the most frequently in the finance category (31\%), and adventure in the travel category ( $42 \%)$.

\section{Discussion}

This study investigated two topics of Chinese advertising. One was the use of rational/emotional appeals and cultural values for Chinese indigenous brands, and the other was the difference in the useacross product categories. While overall there was more use of rational appeals and less use of emotional appeals in goods advertising than 
in service advertising, the use of appeals and cultural values varied within goods categories. There was in fact more use of emotional appeals than rational appeals in the beauty and personal care category and the clothing category, and there was no difference in appeals in the food and drink category. These results were likely due to product characteristics, that is, rational appeals are associated with utilitarian products and emotional appeals are associated with hedonic products (Hoyer \& Maclnnis, 2004).

Cheng and Schweitzer (1996) once hypothesized that Chinese television commercials tended to use more utilitarian cultural values because "China's current stage of development most resembles the United States at an earlier stage of development, when advertising was much more utilitarian and product-oriented" (p. 31), but they did not find strong evidence to support the hypothesis. Given the fact that rational appeals are often paired with functional or utilitarian needs whereas emotional appeals with hedonic or symbolic needs (Hoyer \& Maclnnis, 2004), the results in this study regarding the use of appeals and cultural values further illustrated that the use of cultural values was not necessarily decided by economic development but by product characteristics.

It makes good sense for advertisers to use the appeals and cultural values for the product categories in the manner as identified in this study. Consumers usually use personal products, i.e., fashion apparel, cosmetics, and personal care products, for hedonic needs such as feeling good about themselves (Hoyer \& Maclnnis, 2004); therefore, values that are more emotional best fit consumers' expectation towards and perception of these product categories. In addition, the intangibility of service also makes emotional values the appropriate choice (Swaminathan, Zinkhan, \& Reddy, 1996). Conversely, consumers usually use automobiles, household appliances, and medicine for utilitarian needs (Hoyer \& Maclnnis, 2004), and values that are more rational best fit the expectation and perception from consumers. Food and drink can be used for both hedonic needs such as taste and utilitarian needs such as nutrition (Levy, 1981); therefore, it should be no surprise that the use of the appeals and values are balanced. The expectation toward and perception of these product categories may hold true across cultures, and the findings about Chinese brands in this study, including both the use of rational/emotional appeals and the most frequently used cultural values, should provide Western brands with guidance as to how to advertise in China.

AdMonitor of MeiHua Information's tracking service also includes radio, outdoor, and internet advertising in China, but this study only investigated television advertising. It is important to examine advertising on other media and make cross-media comparisons in future research. Another limitation is that there were no actual perceptions from consumers to further support the interpretations of the use of the appeals and cultural values in this study, and experimental methodologies that ask consumers to report their thoughts and feelings about the commercials should be included in future research. Finally, it is worthwhile to interview advertisers to better understand their perspectives to the use of appeals and valuesacross product categories. In fact, more collaboration between academics and practitioners is a key initiative advocated for future international advertising research (Taylor, 2005).

\section{References}

Albers-Miller, N. D. (1996). Designing cross-cultural advertising research: A closer look at paired comparisons. Internatioanl Marketing Review, 13(5), 59-75. http://dx.doi.org/10.1108/02651339610131397

Albers-Miller, N. D., \& Stafford, M. R. (1999). An international analysis of emotional and rational appeals in services vs goods advertising. Journal of Consumer Marketing, 16(11), 42-57. http://dx.doi.org/10.1108/07363769910250769

Andren, G., Ericsson, L. O., Ohlsson, R., \& Tannsjo, T. (1980). Rhetoric and ideology in advertising: A content analytic study of American advertising. Stockholm: Liber Forlag.

Cheng, H., \& Schweitzer, J. C. (1996). Cultural values reflected in Chinese and U. S. television commercials. Journal of Advertising Research, 36(1), 27-45.

Duncan, T. (2002). IMC: Using advertising and promotion to build brands. New York: McGraw-Hill.

Hofstede, G. H. (1980). Culture's consequences: International differences in work-related values. Newbury Park, CA: Sage.

Hoyer, W. D., \& Maclnnis, D. J. (2004). Consumer behavior (3rd ed.). Boston, MA: Houghton Mifflin.

Levy, S. J. (1981). Interpreting consumer mythology: A structural approach to consumer behavior. Journal of Marketing, 45(3), 49-61. http://dx.doi.org/10.2307/1251541

Lin, C. A. (2001). Cultural values reflected in Chinese and American television advertising. Journal of Advertising, 30(4), 83-94.

Lombard, M., Snyder-Duch, J., \& Bracken, C. C. (2002). Content analysis in mass communication: Assessment 
and reporting of intercoder reliability. Human Communication Research, 28(4), 587-604. http://dx.doi.org/10.1111/j.1468-2958.2002.tb00826.x

Mueller, B. (1987). Reflections of culture: An analysis of Japanese and American advertising appeals. Journal of Advertising Research, 27(3), 51-59.

Mueller, B. (2004). Dynamics of internatinal advertising: Theoretical and practical perspectives. New York: Peter Lang Publishing.

Murray, H. (1938). Explorations in personality. New York, NY: Oxford University Press.

North, R. C., Holster, O., Zaninovich, M. G., \& Zinnes, D. A. (1963). Content analysis: A handbook with applications for the study of international crisis. Evanston, IL: Northwestern University Press.

Pollay, R. W. (1983). Measuring cultural values manifest in advertising. Current Issues and Research in Advertising, 6(1), 71-92.

Rokeach, M. (1973). The nature of human values. New York, NY: Free Press.

Starch, D. (1923). Principles of advertising. New York, NY: McGraw-Hill.

Swaminathan, V., Zinkhan, G. M., \& Reddy, S. K. (1996). The evolution and antecedents of transformational adverrtising: A conceptual model. Advances in Consumer Research, 23, 49-55.

Taylor, C. R. (2005). Moving international advertising research forward. Journal of Advertising, 34(1), 7-16.

Wang, C. C. L. (2000). Right appeals for the "right self": Connectedness-separateness self-schema and cross-cultural persuasion. Journal of Marketing Communications, 6(4), 205-217. http://dx.doi.org/10.1080/135272600750036337

Weber, I. G. (2000). Challenges facing China's television advertising industry in the age of spiritual civilization: An industry analysis. International Journal of Advertising, 19, 259-281. 